\title{
Assessment of Pharmacist Led Patient Counseling Program for Hypertension Management: The Transformative Role of Community Pharmacies in Chronic Disease Management
}

\author{
Madeeha Malik $^{* 1}$, Usman Aslam ${ }^{2}$, Azhar Hussain ${ }^{3}$, Ayisha Hashmi ${ }^{4}$ \\ ${ }^{1}$ Professor/Director, Hamdard Institute of Pharmaceutical Sciences, Hamdard University Islamabad, Pakistan \\ ${ }^{2}$ Hamdard Institute of Pharmaceutical Sciences, Hamdard University Islamabad, Pakistan \\ ${ }^{3}$ Professor/Dean, Faculty of Pharmacy, Hamdard University, Pakistan \\ ${ }^{4}$ Lecturer, Faculty of Pharmacy, Hamdard University, Pakistan
}

Corresponding author: Madeeha Malik, madeehamalik15@gmail.com

Received 30 December 2020;

Accepted 22 January 2021;

Published 01 February 2021

\begin{abstract}
Background: Effective management of hypertension depends on efficacy of therapy as well as patient adherence to medication therapy and nonpharmacological approaches. As one of the important member of primary healthcare team, community pharmacists can play a key role in counseling patients and managing their chronic illnesses. Aim: The objective of the study was to assess the effectiveness of pharmacist counseling on management of hypertension of patients attending community pharmacies in twin cities of Pakistan. Methodology: A randomized, controlled, single blinded, pre-post intervention study design was used. Pharmacists working at community pharmacies included in group A (intervention) were targeted for training while no training was given to the pharmacists working at community pharmacies included in group B (control). The total numbers of patients were 40 in each group while estimating a drop-out rate of $25 \%$. Patients in the intervention group received special counseling sessions by the community pharmacist whereas those in the control group received the usual pharmacy services for six months. Pre-validated tool hypertension knowledge level scale was used to assess disease knowledge. The questionnaire was administered by the pharmacists to the respondents at baseline and after 6 months. Data was cleaned, coded and analyzed in SPSS 21. Results: The results of the present study showed that respondents having hypertension since the past one year had comparatively better knowledge $(23.83, \pm 0.40)$ after six months of counseling. Mean knowledge scores regarding hypertension among intervention group at baseline was $(15.60, \pm 3.33)$ which was improved after six months $(18.35, \pm 2.31)$. The systolic and diastolic blood pressure also improved in intervention group after 6 months of counseling. Significant difference was observed $(\mathrm{p} \leq 0.05)$ in pre-post intervention knowledge regarding hypertension management. Knowledge of patients was improved regarding different aspects of hypertension management after counseling by community pharmacists. Conclusion: The results of the current study concluded that counseling by community pharmacist had a positive impact on hypertension management. Educational programs should be initiated by community pharmacists as this can lead to improvement in blood pressure goals, disease knowledge and medication adherence and enhance the image of pharmacist as a key health care member in management of chronic diseases.
\end{abstract}

Keywords: Hypertension, community pharmacist, Pakistan, intervention

\section{Introduction}

The disease burden due to chronic illnesses is rapidly increasing with $60 \%$ of the deaths attributed to such diseases. Globally, the disease burden due to chronic diseases is estimated to be $46 \%$ of the total disease burden. Among the chronic illnesses, cardiovascular diseases, obesity and diabetes contribute to approximately half of the burden of chronic diseases ${ }^{[1]}$. The most prevalent chronic and communicable diseases affecting majority of the individuals residing in developed as well as developing countries is hypertension (HTN) ${ }^{[2]}$.

Hypertension is a common health problem in developed as well as developing countries and a major risk factor for cardiovascular diseases (CVD). Hypertension is considered to be the foremost cause of increased mortality and disability among elderly patients ${ }^{[3]}$. Approximately one billion individuals are suffering from hypertension and it is estimated that the number will rise to 1.56 billion by the year $2025^{[4]}$. It has been estimated that $18 \%$ of adult population and $45 \%$ aged above 45 years are 
currently suffering from hypertension ${ }^{[5]}$. Due to existence of hypertension, there are increased chances of development of cardiovascular disorders, retinopathy and nephropathy ${ }^{[6]}$. Despite the introduction of new pharmacotherapy approaches, the optimal control of blood pressure and lipid profile remains poor in patients diagnosed with hypertension. In order to decrease the risk of acute and chronic complications, the approach to treatment includes a combination of medicines, diet controol, and physical activity along with self-care ${ }^{[7]}$.

A number of barriers have been identified leading to ineffective management of hypertension ${ }^{[8]}$. One of the major barrier hindering effective management of hypertension is patient non-adherence to lifestyle modifications and medications. The major barriers to medication adherence include complex therapeutic plans, difficulty in understanding medical prescriptions, socioeconomic aspects, lack of knowledge regarding the disease and medications, lack of motivation to change and limited health literacy ${ }^{[9]}$. Effective management of hypertension depends on efficacy of therapy as well as patient adherence to medication therapy and non-pharmacological approaches. One of the most important tools to improve patient adherence is counseling. Counseling plays an important role in enhancing medication adherence and optimizing medication therapy. As the most important contact point for patients, community pharmacists can play a major role in improving the management of hypertension and enabling patients to achieve their pharmacotherapy goals. Their role in hypertension treatment is of utmost importance as they can help patients in optimizing their lifestyle and medication therapy. Thus the objective of the study was to assess the effectiveness of pharmacist counseling on blood pressure control of hypertensive patients attending community pharmacies in Pakistan.

\section{Methodology}

\section{Study Design and Respondents}

A randomized, controlled, single blinded, pre-post intervention study design was used to assess the effectiveness of pharmacist counseling on management of hypertension of patients attending community pharmacies in twin cities of Pakistan. The study sites were community pharmacies situated in twin cities (Islamabad and Rawalpindi) of Pakistan. The respondents included patients diagnosed with hypertension (Stage I or II) visiting community pharmacies for purchasing their regular medicine.

\section{Ethical Approval}

Study approval was taken from the Ethical Committee of Hamdard University (ref no BASAR.9.1.264). Approval was also taken from respective proprietors of different community pharmacies from which data had been collected. Besides this, consent was also taken from the respondents and their confidentiality of information was also assured.

\section{Sampling and Sample Size}

Community pharmacies of twin cities which were selected in pre intervention phase were eight. Simple random sampling technique by lottery method was used to select community pharmacies to be included in group A (intervention $n=4$ ) and group B (control $n=4$ ). Pharmacists working at community pharmacies included in group a (intervention) were targeted for training while no training was given to the pharmacists working at community pharmacies included in group B (control). According to WHO, at least thirty encounters must be included in each group to assess the impact of intervention (World Health Organization, 1993). The total numbers of patients were 40 in each group while estimating a drop-out rate of $25 \%$. Convenience sampling technique was used to select patients visiting community pharmacies. Ten patients were selected at each community pharmacy after taking their consent to participate in the study.

\section{Intervention Design and Format}

The focus, targets, contents and format of intervention were designed after a series of discussions with different stakeholders. The content of the training material was developed from Pharmacy-Based Hypertension Management Model: Protocol and Guidelines (WHO, 2005) and JNC-8 guidelines for management of Hypertension. The pharmacists were also provided with brochures and one pagers related to hypertension management and counseling, blood pressure log sheets, BP measuring devices and questionnaires for assessment of hypertension knowledge. The pharmacists were also provided patient kits which comprised of brochures of diseases, diet charts and BP monitoring cards.

Patients in the intervention group received special counseling sessions by the community pharmacist whereas those in the control group received the usual pharmacy services i.e. dispensing of medications and provision of information regarding to administration of medications. The patients enrolled in the control and intervention group were required to visit the community pharmacy after every fifteen days for six months during the course of study. At the enrollment, patients in intervention group received counseling about disease, its complications, medication, lifestyle modifications and self-monitoring of the disease. Each patient also received consultations based on individual needs. Patient kits were provided along with counseling. The duration of counseling was minimum 20 minutes. Blood pressure in both control and intervention groups at each visit. Pharmacist reinforced the intervention about the lifestyle modifications, medication adherence, and self-monitoring on each visit. The principal investigator also counseled the patients in intervention group through tele-monitoring during the course of the study

\section{Data Collection Tool}

Pre-validated tool was used for the study. Written permission had been obtained from respective organization. The pre-validated tool used for assessment of hypertension knowledge was Hypertension Knowledge-Level Scale (Erkoc etal, 2012). The questionnaire comprised of twenty two questions related to definition, drug compliance, lifestyle, diet and complications. The scoring of the HK-LS included the sum of all the correct items of each respondent. One point was given to each correct answer and no point for the incorrect option. The score range of the tool is $0-22$, the higher score indicates better patient knowledge regarding hypertension.

\section{Data Analysis}

Data was collected by the community pharmacists trained by the principal investigator. The questionnaire was administered by the pharmacists to the respondents at baseline and after 6 months. Blood pressure was monitored by selected community pharmacists after every 15 days for 6 months. After data collection, data was cleaned, coded and entered in SPSS version-21. Wilcoxon test $(\mathrm{p} \geq 0.05)$ was used to compare pre-post intervention knowledge regarding hypertension.

\section{Results}

\section{Demographic Characteristics}

Out of 40 respondents of control group, $52.5 \%(n=21)$ were males whereas $47.5 \%(n=19)$ were females. Of the total respondents in 
control group, $2.5 \%(n=1)$ had completed matric, $20 \%(n=8)$ had completed intermediate, $30 \%(n=12)$ were graduated, $40 \%(n=16)$ had completed post-graduation and $7.5 \%(n=3)$ were illiterate. Majority of the respondents had a history of hypertension for more than 6 years $(42.5 \%, n=17)$ whereas $40 \%(n=16)$ had diabetes since past 4-6 years. Out of 40 respondents of intervention group, $67.5 \%$ $(n=27)$ were males whereas $32.5 \%(n=13)$ were females. Of the total respondents in intervention group, $25 \%(\mathrm{n}=10)$ had completed matric, 25\% ( $\mathrm{n}=10)$ had completed intermediate, 32.5\% ( $\mathrm{n}=13)$ were graduated, $2.5 \%(\mathrm{n}=1)$ had completed post-graduation and $15 \%(n=6)$ were illiterate. Majority of the respondents had a history of hypertension for more than 6 years $(62.5 \%, \mathrm{n}=25)$. A detailed description is given (Table 1).

Table 1 Demographic Characteristics

\begin{tabular}{|l|l|l|}
\hline $\begin{array}{l}\text { Demographic } \\
\text { Characteristics }\end{array}$ & $\begin{array}{l}\text { Control Group } \\
\mathbf{n}(\boldsymbol{\%})\end{array}$ & $\begin{array}{l}\text { Intervention } \\
\text { Group n (\%) }\end{array}$ \\
\hline Age & 0 & 0 \\
\hline 20-30 years & $8(20)$ & $6(15)$ \\
\hline 31-40 years & $18(45)$ & $11(27.5)$ \\
\hline 41-50 years & $9(22.5)$ & $21(52.5)$ \\
\hline 51-60 years & $5(12.5)$ & $2(5)$ \\
\hline$>60$ years & $21(52.5)$ & $27(67.5)$ \\
\hline Gender & $19(47.5)$ & $13(32.5)$ \\
\hline Male & $1(2.5)$ & $10(25)$ \\
\hline Female & $8(20)$ & $10(25)$ \\
\hline Level of Education & $12(30)$ & $13(32.5)$ \\
\hline Matric & $16(40)$ & $1(2.5)$ \\
\hline Intermediate & & \\
\hline Graduate &
\end{tabular}

\begin{tabular}{|c|c|c|}
\hline Illiterate & $3(7.5)$ & $6(15)$ \\
\hline \multicolumn{3}{|c|}{ Duration of Hypertension } \\
\hline$<1$ year & 0 & $3(7.5)$ \\
\hline $1-3$ years & 7 (17.5) & $5(12.5)$ \\
\hline 4-6 years & $16(40)$ & $7(17.5)$ \\
\hline$>6$ years & $17(42.5)$ & $25(62.5)$ \\
\hline \multicolumn{3}{|l|}{ Income Level } \\
\hline$<$ Rs. 10,000 & 0 & $2(5)$ \\
\hline Rs.10,000-20,000 & 0 & $1(2.5)$ \\
\hline Rs.21,000-30,000 & $4(10)$ & $3(7.5)$ \\
\hline Rs. $31,000-40,000$ & $14(35)$ & 0 \\
\hline Rs.41,000-50,000 & $12(30)$ & $2(5)$ \\
\hline$>$ Rs. 50,000 & $10(25)$ & $32(80)$ \\
\hline
\end{tabular}

Mean Scores of Pre and Post Intervention Knowledge regarding Hypertension after Community Pharmacist Counseling

The results of the present study showed that respondents having age 41-50 years had better hypertension knowledge scores (18.54, \pm 1.12 ) after six months of community pharmacist counseling. Females had comparatively better knowledge scores of hypertension $(18.61, \pm 2.59)$ than males $(18.22, \pm 2.20)$ after six months of counseling. Respondents having intermediate education had comparatively better knowledge scores $(19.70, \pm 1.63)$ after six months of counseling. Respondents having hypertension since the past 1-3 years had comparatively better knowledge scores (19.20, \pm 2.58 ) after intervention. Respondents having income Rs.1000020000 had comparatively better knowledge scores $(19.75, \pm 1.50)$ after six months of counseling. No improvement was observed in knowledge scores among control group over the period of six months. A detailed description is given (Table 2).

Table 2: Comparison of Pre and Post Intervention Knowledge regarding Hypertension after Community Pharmacist Counseling

\begin{tabular}{|c|c|c|c|c|}
\hline \multirow{3}{*}{ Demographic Variables } & \multicolumn{4}{|c|}{ Knowledge regarding Hypertension (Score Range:0-22) } \\
\hline & \multicolumn{2}{|c|}{ Control Group } & \multicolumn{2}{|c|}{ Intervention Group } \\
\hline & Baseline & After 6 Months & Baseline & After 6 Months \\
\hline Age & & & & \\
\hline $31-40$ years & $14.75( \pm 2.71)$ & $14.37( \pm 2.50)$ & $11.83( \pm 4.95)$ & $17.00( \pm 3.74)$ \\
\hline $41-50$ years & $14.66( \pm 1.97)$ & $14.22( \pm 2.26)$ & $16.63( \pm 1.91)$ & $18.54( \pm 1.12)$ \\
\hline $51-60$ years & $15.11( \pm 2.93)$ & $15.00( \pm 2.95)$ & $15.80( \pm 2.76)$ & $18.38( \pm 2.24)$ \\
\hline$>60$ years & $13.80( \pm 3.49)$ & $13.40( \pm 2.19)$ & $14.60( \pm 4.82)$ & $18.20( \pm 2.94)$ \\
\hline \multicolumn{5}{|l|}{ Gender } \\
\hline Male & $14.47( \pm 2.83)$ & $14.14( \pm 2.59)$ & $15.59( \pm 3.14)$ & $18.22( \pm 2.20)$ \\
\hline Female & $14.89( \pm 2.07)$ & $14.52( \pm 2.26)$ & $15.61( \pm 3.84)$ & $18.61( \pm 2.59)$ \\
\hline \multicolumn{5}{|l|}{ Level of Education } \\
\hline Matric & $14.00( \pm 2.45)$ & $14.28( \pm 2.15)$ & $15.80( \pm 1.03)$ & $18.50( \pm 0.70)$ \\
\hline Intermediate & $15.12( \pm 3.18)$ & $15.50( \pm 2.77)$ & $16.90( \pm 2.64)$ & $19.70( \pm 1.63)$ \\
\hline Graduate & $15.25( \pm 1.71)$ & $14.58( \pm 1.78)$ & $15.76( \pm 3.39)$ & $18.00( \pm 2.61)$ \\
\hline Postgraduate & $14.37( \pm 2.52)$ & $13.68( \pm 2.67)$ & $15.81( \pm 3.33)$ & $18.37( \pm 2.44)$ \\
\hline Illiterate & $13.00( \pm 3.60)$ & $13.66( \pm 2.51)$ & $13.33( \pm 6.35)$ & $16.83( \pm 3.54)$ \\
\hline \multicolumn{5}{|l|}{ Duration of Hypertension } \\
\hline$<1$ year & 0 & 0 & $8.00( \pm 3.46)$ & $14.66( \pm 3.78)$ \\
\hline $1-3$ years & $14.71( \pm 2.21)$ & $14.71( \pm 2.21)$ & $16.60( \pm 4.27)$ & $19.20( \pm 2.58)$ \\
\hline 4-6 years & $14.12( \pm 2.68)$ & $13.50( \pm 2.47)$ & $14.85( \pm 4.05)$ & $18.14( \pm 3.48)$ \\
\hline$>6$ years & $15.17( \pm 2.42)$ & $14.94( \pm 2.35)$ & $16.52( \pm 1.19)$ & $18.68( \pm 1.18)$ \\
\hline \multicolumn{5}{|l|}{ Income Level } \\
\hline$<$ Rs. 10,000 & 0 & 0 & $16.00( \pm 4.15)$ & $18.50( \pm 0.70)$ \\
\hline Rs.21,000-30,000 & $15.75( \pm 0.95)$ & $16.00( \pm 0.81)$ & $18.25( \pm 0.95)$ & $19.75( \pm 1.50)$ \\
\hline Rs.31,000-40,000 & $14.85( \pm 2.50)$ & $14.21( \pm 2.39)$ & $15.28( \pm 3.29)$ & $17.92( \pm 2.52)$ \\
\hline Rs.41,000-50,000 & $14.25( \pm 3.04)$ & $14.16( \pm 2.32)$ & $14.58( \pm 4.23)$ & $17.66( \pm 2.70)$ \\
\hline$>$ Rs. 50,000 & $14.50( \pm 2.27)$ & $14.00( \pm 2.98)$ & $16.20( \pm 2.29)$ & $19.20( \pm 1.31)$ \\
\hline
\end{tabular}

Score range: 0-22 (Higher mean score indicates better knowledge whereas lower mean score indicates poor knowledge) 


\section{Impact of Pharmacist Counselling on Knowledge of Patients Regarding Hypertension}

Significant difference was observed ( $\mathrm{n} \geqq 0.05$ ) in pre-post intervention knowledge regarding hypertension management. Knowledge of patients was improved regarding different aspects of hypertension management after counseling by community pharmacists. A detailed description is given (Table 3).

Table 3: Impact of Pharmacist Counselling on Knowledge of Patients Regarding Diabetes Mellitus and Hypertension

\begin{tabular}{|c|c|c|c|c|c|c|}
\hline \multirow[t]{2}{*}{ Knowledge } & & \multirow[t]{2}{*}{$\mathbf{n}$} & \multirow[t]{2}{*}{ Mean Rank } & \multirow[t]{2}{*}{ Sum of Ranks } & \multicolumn{2}{|c|}{ Hypertension Knowledge } \\
\hline & & & & & z-value & p-value \\
\hline \multirow{4}{*}{$\begin{array}{l}\text { Hypertension } \\
\text { Knowledge }\end{array}$} & Negative ranks & 2 & 6.00 & 12.00 & \multirow{4}{*}{-5.245} & \multirow{4}{*}{0.001} \\
\hline & Positive ranks & 36 & 20.25 & 729.00 & & \\
\hline & Ties & 2 & & & & \\
\hline & Total & 40 & & & & \\
\hline
\end{tabular}

Wilcoxon Test $(p \geq 0.05)$

Comparison of Impact of Community Pharmacist Counseling on Blood Pressure at Baseline, Three Months and Six Months among Control and Intervention Group

The results of the study showed that at baseline, the mean systolic blood pressure among control $(131.45, \pm 9.84)$ and intervention group $(136.85, \pm 10.98)$ was similar. The systolic BP increased among control group after three months $(136.75, \pm 7.47)$ and six months $(143.48, \pm 6.37)$. On the other hand, the systolic BP decreased among intervention group at three months $(132.28$, $\pm 10.69)$ and six months $(127.63, \pm 6.88)$. The mean diastolic BP increased among control group from baseline $(91.00, \pm 8.10)$ at three months $(93.50, \pm 8.10)$ and six months $(95.00, \pm 6.40)$. A detailed description is given (Table 4).

Table 4: Comparison of Impact of Community Pharmacist Counseling on Blood Pressure at Baseline, Three Months and Six Months among Control and Intervention Group

\begin{tabular}{|l|l|l|l|l|l|l|}
\hline \multirow{2}{*}{ Indicators } & \multicolumn{2}{|l|}{ Intervention Group } & \multicolumn{3}{l|}{} \\
\cline { 2 - 7 } & Baseline & 3 Months & 6 Months & Baseline & 3 Months & 6 Months \\
\hline $\begin{array}{l}\text { Systolic BP }(\mathbf{m m H g}) \\
\text { Mean } \pm \text { SD }\end{array}$ & $131.45( \pm 9.84)$ & $136.75( \pm 7.47)$ & $143.48( \pm 6.37)$ & $136.85( \pm 10.98)$ & $132.28( \pm 10.69)$ & $127.63( \pm 6.88)$ \\
\hline $\begin{array}{l}\text { Diastolic BP }(\mathbf{m m H g}) \\
\text { Mean } \pm \text { SD }\end{array}$ & $91.00( \pm 8.10)$ & $93.50( \pm 8.10)$ & $95.00( \pm 6.40)$ & $92.08( \pm 10.69)$ & $86.68( \pm 6.17)$ & $82.63( \pm 5.18)$ \\
\hline
\end{tabular}

\section{Discussion}

Community pharmacies are easily accessible to the public and are located in every area, so they serve as an excellent site for patient counseling and provision of pharmaceutical care ${ }^{[13]}$. Community pharmacists can play an important role in management of hypertension by assisting patients in achieving therapeutic and lifestyle goals ${ }^{[14]}$. The results of the present study showed improvements in management and control of hypertension after six months counseling of patients by community pharmacist. The results of the present study showed that the knowledge regarding hypertension improved over a six months period in intervention group who received counseling from community pharmacist. The post-intervention group had better knowledge regarding disease, lifestyle changes, medication use and complications of hypertension. Similar findings were reported in a study conducted in Australia where the knowledge regarding hypertension improved after counseling by community pharmacist ${ }^{[3]}$. On the other hand, the findings of the present study reported no improvement in knowledge regarding hypertension among control group over time. Similar results were observed in a study conducted in USA where no improvement in knowledge among control group was observed [6].

For successful management of hypertension, it is necessary that a community pharmacist periodically monitors level of knowledge and drug related problems among patients (Chung etal, 2014). The results of the current study showed that knowledge of young patients regarding hypertension improved significantly as compared to elderly. This might be due to the fact that elderly patients had difficulty in understanding and memorizing the information regarding disease and its management. A study conducted in Brazil reported similar results where younger adults had better knowledge scores for hypertension management after intervention as compared to older adults ${ }^{[15]}$. The results of the present study reported that females had comparatively better postintervention hypertension knowledge than males. Similar findings were reported in studies conducted in Ghana and Egypt where improvement in knowledge was reported post-intervention by community pharmacist ${ }^{[16]}$. On the other hand, the present study showed that better qualification helped in improvement in knowledge of disease management after counseling by community pharmacist. Similar results were reported in a study conducted in India where patients having better qualification reported improved knowledge after counseling by community pharmacist ${ }^{[10]}$.

Pharmaceutical care programs initiated by community pharmacist can lead to improvement of blood pressure goals ${ }^{[17]}$. Intervention group showed a significant decrease in systolic blood pressure as compared to control group after period of three and six months. Furthermore, significant reduction was also observed in diastolic blood pressure in intervention group. Majority of the patients achieved the targeted systolic and diastolic blood pressure goals. Reduction in blood pressure was observed among all demographic variables. Similar findings were reported in studies conducted in Malaysia, Turkey and Brazil where improvement in blood pressure was observed $^{[18]}$.

\section{Conclusion}

The current study provided a valuable insight regarding the benefits of inclusion of community pharmacist in hypertension health care team. The results of the current study concluded that counseling by community pharmacist has a positive impact on blood pressure management among hypertensive patients. The knowledge of disease management improved after a six months 
intervention by community pharmacists. Better qualification and income also helped in perceiving the counseling positively and improved hypertension management. Thus community pharmacist counseling helped patients in achieving their desired blood pressure and blood glucose goals as well as medication adherence was also improved. Educational programs should be initiated by community pharmacists as this can lead to improvement in blood pressure and enhance the image of pharmacist as a key health care member in management of chronic diseases.

\section{Limitations}

Few of the limitations faced during conduction of this study included time and financial constraints. The respondents were followed up for only six months so the long term benefits of this community pharmacy model could not be observed at length. The study may not be generalized to other parts of the country as it was conducted within twin cities of Pakistan.

\section{References}

[1] Jahangard-Rafsanjani, Z., et al., Effect of a Community Pharmacist-Delivered Diabetes Support Program for Patients Receiving Specialty Medical Care: A Randomized Controlled Trial. The Diabetes Educator, 2015. 41(1): p. 127-135.

[2] Cheema, E., P. Sutcliffe, and D.R. Singer, The impact of interventions by pharmacists in community pharmacies on control of hypertension: a systematic review and meta-analysis of randomized controlled trials. British journal of clinical pharmacology, 2014. 78(6): p. 12381247.

[3] Bajorek, B., et al., Implementation and evaluation of a pharmacist-led hypertension management service in primary care: outcomes and methodological challenges. Pharmacy Practice (Granada), 2016. 14(2): p. 0-0.

[4] Bajorek, B.V., et al., Management of hypertension in an Australian community pharmacy setting-patients' beliefs and perspectives. International Journal of Pharmacy Practice, 2017. 25(4): p. 263-273.

[5] Saleem, F., et al., Pharmacist intervention in improving hypertension-related knowledge, treatment medication adherence and health-related quality of life: a nonclinical randomized controlled trial. Health Expectations, 2015. 18(5): p. 1270-1281.

[6] Bunting, B.A., B.H. Smith, and S.E. Sutherland, The Asheville Project: clinical and economic outcomes of a community-based long-term medication therapy management program for hypertension and dyslipidemia. Journal of the American Pharmacists Association, 2008. 48(1): p. 23-31.

[7] Korcegez, E.I., M. Sancar, and K. Demirkan, Effect of a pharmacist-led program on improving outcomes in patients with type 2 diabetes mellitus from Northern Cyprus: a randomized controlled trial. Journal of managed care \& specialty pharmacy, 2017. 23(5): p. 573582.

[8] Skowron, A., S. Polak, and J. Brandys, The impact of pharmaceutical care on patients with hypertension and their pharmacists. Pharmacy practice, 2011. 9(2): p. 110.
[9] Obreli-Neto, P.R., et al., Effect of a 36-month pharmaceutical care program on pharmacotherapy adherence in elderly diabetic and hypertensive patients. International journal of clinical pharmacy, 2011. 33(4): p. 642-649.

[10] Marfo, A.F.A. and F.T. Owusu-Daaku, Exploring the extended role of the community pharmacist in improving blood pressure control among hypertensive patients in a developing setting. Journal of pharmaceutical policy and practice, 2017. 10(1): p. 39.

[11] Nam, S., et al., Barriers to diabetes management: patient and provider factors. Diabetes research and clinical practice, 2011. 93(1): p. 1-9.

[12] Carter, B.L., et al., Physician and pharmacist collaboration to improve blood pressure control. Archives of internal medicine, 2009. 169(21): p. 19962002.

[13] Laliberté, M.-C., et al., Ideal and actual involvement of community pharmacists in health promotion and prevention: a cross-sectional study in Quebec, Canada. BMC public health, 2012. 12(1): p. 192.

[14] Okada, H., et al., Effects of lifestyle intervention performed by community pharmacists on glycemic control in patients with type 2 diabetes: The Community Pharmacists Assist (Compass) Project, a pragmatic cluster randomized trial. Pharmacology \& Pharmacy, 2016. 7(03): p. 124.

[15] de Souza Cazarim, M., et al., Impact assessment of pharmaceutical care in the management of hypertension and coronary risk factors after discharge. PloS one, 2016. 11(6): p. e0155204.

[16] Júnior, L., P.S. Marcellini, and I.R. Pelá, Effect of pharmaceutical care intervention on blood pressure of elderly outpatients with hypertension. Revista Brasileira de Ciências Farmacêuticas, 2008. 44(3): p. 451-457.

[17] Morgado, M., S. Rolo, and M. Castelo-Branco, Pharmacist intervention program to enhance hypertension control: a randomised controlled trial. International journal of clinical pharmacy, 2011. 33(1): p. 132-140.

[18] Margolis, K.L., et al., Effect of home blood pressure telemonitoring and pharmacist management on blood pressure control: a cluster randomized clinical trial. Jama, 2013. 310(1): p. 46-56.

[19] Fikri-Benbrahim, N., et al., Impact of a community pharmacists' hypertension-care service on medication adherence. The AFenPA study. Research in Social and Administrative Pharmacy, 2013. 9(6): p. 797-805.

[20] Carter, B.L. and J. Foppe van Mil, Comparative effectiveness research: evaluating pharmacist interventions and strategies to improve medication adherence. American journal of hypertension, 2010. 23(9): p. 949-955.

[21] Lau, R., et al., Evaluation of a community pharmacybased intervention for improving patient adherence to antihypertensives: a randomised controlled trial. BMC health services research, 2010. 10(1): p. 34. 